\title{
Tribunales Provinciales de lo Contencioso Administrativo
}

Ante los rumores insistentes que a nuestro retiro en provincia nos llega sobre la supresión de estos Tribunales con la creación de otros de ámbito regional, aun conociendo nuestra insignificancia $y$ falta de autoridad, nos permitimos hacer algunas reflexiones sobre este tema, apoyándonos para ello en la experiencia de más de treinta años de ininterrumpida actuación, en los que la práctica nos ha brindado tantas instructivas observaciones que estimamos conveniente condensar de una manera breve y sencilla, prescindiendo, dada la índole del trabajo, de recoger las valiosas aportaciones doctrinales de ilustres tratadistas que con tanto afán, y en algunos casos con notoria autoridad, se han expuesto en estos últimos tiempos.

En la historia, ya casi centenaria, de estos Tribunales provinciales contencioso-administrativos, es obligado considerarlos como una de las más acertadas creaciones para un buen régimen jurídico, tanto como amparo ciudadano como estímulo y poderoso acicate para un recto obrar de la Administración pública. Su eficacia ha sido extraordinaria y han servido en mil ocasiones para que la injusticia y la arbitrariedad no prevalezcan, logrando que impere el orden en la gestión pública y el respeto a derechos e intereses sagrados, tanto de la Administración como de los particulares.

Cabe señalar en la actuación de estos Tribunales una larga etapa cie esplendor y de relevancia social extraordinaria. Su eficacia ha sido mayor en los momentos de intensa ciudadanía, en aquellos en que las convulsiones políticas despertaron acciones incompati- 
bles con la justicia. Estos Tribunales se cubrieron de g'oria en su actuación, especialmente en la etapa que se inicia con la promulgación del Estatuto municipal, y alcanza su mayor esplendor durante los años de la Segunda República. No es para dicha el ansia de venganza que surgió al constituirse las Corporaciones municipales republicanas por aquel arbitrario Decreto del Gobierno provisional, anulando las Corporaciones monárquicas; por todas partes se descubrían malversaciones, arbitrariedades, draconianas medidas antirreligiosas y determinaciones llenas de odios y de venganzas, para eliminar monumentos de sabor monárquico o religiosos, etc. Ello determinó un número extraordinario de recursos contenciosoadministrativos, que fueron cumplidamente tramitados y resueltos con toda escrupulosidad; sus sentencias evitaron que se consumase la iniquidad en mil casos y que prevaleciese la injusticia en otros. Estos 'Tribunales provinciales se superaron y, a pesar del cúmulo de actuaciones que se promovieron, como decimos, cumplieron su cometido. Algo parecido ocurrió cuando promulgado el Estatuto municipal al aplicarse las normas establecidas sobre actuación de las Corporaciones locales, tuvo especial ensanchamiento el ámbito de acción de los Ayuntamientos. La actividad municipal se extendió a zonas antes vedadas, se eliminó el régimen de alzada ante la Diputación provincial y ello determinó un aumento considerable, verdaderamente extraordinario, de recursos contencioso-administrativos, que, como decimos, fueron perfectamente resueltos por los respectivos Tribunales.

Después se ha normalizado la actuación y ha descendido considerablemente el número de estos recursos, por tanto, parece injustificado el intento de suprimirlos, en un momento en que, el quehacer de estos Tribunales ha descendido en más de un 50 por 100 , con relación a la actividad que desplegaron en el decenio 1925 a 1935. Extremos éstos de fácil comprobación en cualquier Tribunal provincial o por el estudio de la estadística.

La actividad de los Tribunales provinciales contencioso-administrativos, según los datos estadísticos cuidadosamente comprobados, que figuran en las estadísticas oficiales, se refleja perfectamente por el número de sentencias dictadas durante todo un año; agru- 
pados éstos por Audiencias territoriales y refiriéndonos al año 1949, el número de sentencias dictadas en cada uno de estos Tribunales fué el siguiente (1):

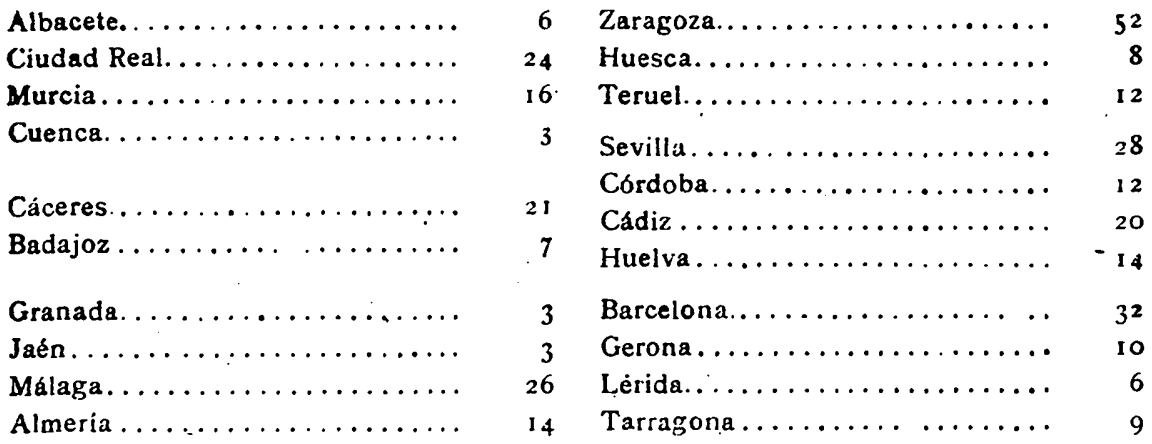

En. el año judicial de 1953-54, los asuntos terminados por los Tribunales provinciales que se mencionan fueron los siguientes:

\begin{tabular}{|c|c|c|}
\hline 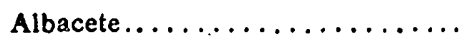 & 10 & Zaragoza $\ldots \ldots \ldots \ldots \ldots \ldots$ \\
\hline Ciudad Real................ & 6 & 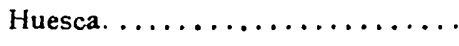 \\
\hline 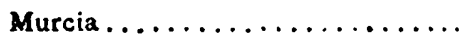 & 5 & 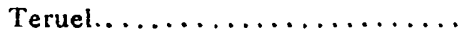 \\
\hline 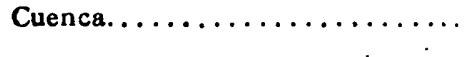 & II & Sevilla.............. \\
\hline & & Cádiz $\ldots \ldots \ldots \ldots \ldots \ldots \ldots \ldots$ \\
\hline Cáceres................ & I6 & Córdoba... \\
\hline Badajoz .................. & 42 & 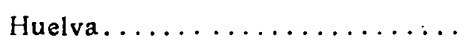 \\
\hline 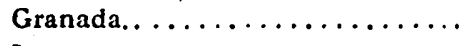 & 17 & Barcelona.... \\
\hline 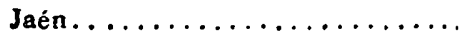 & 17 & 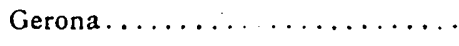 \\
\hline 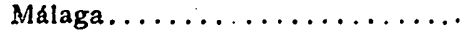 & 29 & 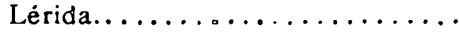 \\
\hline 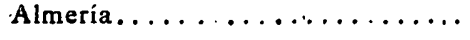 & 19 & 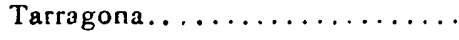 \\
\hline
\end{tabular}

El principio de inmediación aconseja igualmente la subsistencia de los Tribunales provinciales. Los órganos de justicia deben estar en contacto lo más próximo posible a los interesados en los negocios jurídicos sometidos al conocimiento de dichos Tribunales. El alejamiento es pernicioso en alto grado.

Esto tiene especial importancia, tratándose de la jurisdicción

(1) Vid. Las Memorias de los Fiscales del T. S. y los cuadros que se acompañan a los Discursos de apertura de Tribunales. 
contencioso-aciminstrativa, plies facinica ai juzgacior é corocimie:to difuso de :o que hay en el foncio de los asuntos que llegan a estos Tribunales y facilita captar el sentido cie justicia que haya en ios mismos, que no siempre se refleja en las frías actuaciones de un expediente administrativo, sobre todo en los que elaboran las Corporaciones municipales. Es natural, que si el Tribunal actúa en la cabecera del territorio muchos de los asuntos que afecten a localidades alejadas no llegan en toda su magnitud al ámbito del Tribuna: regional. Si el Tribunal se sitúa en Zaragoza, es difícil que pueda recoger el ambiente social, el espíritu popular manifestado en una actuación de un organismo administrativo que actúe en Huesca c Teruel, mientras que a estos Tribunales provinciales inevitablemente les es dado conocer lo que haya de razón y las repercusiones sociales que el hecho enjuiciado pueda tener. El carácter público que tiene esta jurisdicción determina que en muchos casos juegue un papel decisivo el conocer las repercusiones de tipo político social que el acto revisado pueda tener, y que ello precisamente sirva para descubrir las motivaciones determinantes de la resolución administrativa, que con apariencias formales de legalidad puede implicar grave injusticia en el fondo.

Es más fácil al Tribunal provincial de Almería conocer en su intimidad el contenido jurídico de una resolución de los órganos administrativos que actúan. en la capital, que si la revisión de estos acuerdos lo hace un Tribunal radicado en Granada, y lo mismo acontece cuando el acuerdo impugnado procede de un Ayuntamiento de dicha provincia, cuyas actividades, en cierto modo, tienen ya un sello de arbitrariedad o de corrección jurídica que puede ser, como decimos, un buen elemento de juicio para alcanzar un fallo justo.

Es peligroso alejar los Tribunales contenciosos, llevándolos a la cabecera de la región desconectada por mil cáusas de la vida y de las actividades de la Administración pública de cada provincia, y muy particularmente la de sus Ayuntamientos, que por su continua relación con la Diputación provincial, con su Gobierno civil, con los distintos organismos de la Administración provincial, tienen sus agencias en la capital respectiva y, por ende, la relación y con- 
tacto con el Tribunal provincial es mayor, es más intensa y, como antes decimos, es mucho más fácil conocer el contenido y elabo ración del acto administrativo que se someta a revisión ante la jurisdicción contencioso-administrativa.

Esta consideración tiene mayor interés, precisamente dado el sistema imperante en nuestros días, del crecimiento intenso de la actividad administrativa, su continuo roce con los administrados, no siempre amparados convenientemente. Ante la falta de una fiscalización política eficiente, que controle la actuación de las Corporaciones locales, es útil al menos poder captar y recoger las verdaderas motivaciones del acto o resolución impugnado, así como las incidencias habidas en su elaboración, que pueden determinar motivos anulatorios y que corrientemente no se reflejan en las frías actuaciones del expediente administrativo, no obstante la cuidadosa reglamentación que ofrecen algunos reglamentos de procedimientos.

Hay, además, una razón que pudiéramos denominar de respeto a la tradición. $Y$ es el hecho indudable de que si estos Tribunales llevan ya más de medio siglo de actuación, con acierto evidente, habiendo arraigado en nuestro régimen jurídico, con las consiguientes repercusiones en la organización de las Audiencias provinciales, en los Colegios de Abogados de provincia, no parece razonable que se desconozca esta realidad y se modifique desplazando estos Tribunales, ya que ello motivaría indiscutiblemente perturbaciones en el servicio, con obligados desplazamientos para los funcionarios domiciliados en la respectiva capital, y con perjuicio indudable para los Letrados que integran los Colegios de Abogados de las capitales de provincia y que iban a verse privadas de su respectivo Tribunal.

Además de esta razón de tipo tradicional, abona la permanencia de los Tribunales provinciales otros motivos de tipo politico, que no deben olvidarse. La supresión de los Tribunales provinciales significaría para las 50 capitales de provincia que los perdiesen una incudable degradación, una mortificación innecesaria, ya que no responde a ninguna exigencia del servicio público, a ninguna razón que justifique tal supresión, y, por tanto, es de la mayor conveniencia política evitar esa mortificación a estas ciudades es- 
pañolas de las que poco a poco van desapareciendo organismos oficiales, no siempre por auténticas exigencias del servicio público, sino más bien por conveniencia de los funcionarios públicos o de las esposas de éstos, empeñadas en vivir en la media docena de grandes poblaciones, aunque luego, para realizar el servicio público, como acontece, por ejemplo, con el servicio del Instituto de Colonización, ello ocasiona grandes dispendios al Tesoro público obligado a pagar dietas, salidas, locomoción, y el servicio desde luego acuse la deficiencia natural de la falta de permanencia y asidua vigilancia de los jefes.

Los Tribunales provinciales con la organización que dió el Estatuto municipal, fueron consagrados como pieza básica para la buena Administración local por don José Calvo Sotelo, quien en repetidas ocasiones así lo manifestó, y si ahora nos encontramos empeñados en perpetuar esta figura prócer, entiendo que la mejor manera de hacerlo es conservando su obra. Mejor que un monumento de piedra es perpetuar sus creaciones y llevar a realidad aquel pensamiento que iluminó la nueva ordenación jurídica que en el Estatuto y en su Reglamento dió a la vida local española, y de todo ello conservar y mantener pujante los Tribunales provinciales de lo contencioso-administrativo, y en los que el gran Calvo Sotelo veía la mayor garantía para una recta y ordenada actuación de las Corporaciones locales.

Hay, además, razones de tipo económico que abonan la conservación y subsistencia de los Tribunales provinciales. La creación de Tribunales regionales supondría una carga extremadamente onerosa, y sería un gasto cuantioso, que entendemos puede evitarse. Ciertamente que no rinde hoy el Tribunal provincial. quizá lo cue debiera, mas ello es fácil de lograr con un mínimo dispendio de tipo económico para dotarlos convenientemente, ya que es lastimoso no sè alcance la dotación económica necesaria para un perfecto y normal funcionamiento. Bastaría un pequeño estímulo económico para retribuir esta función especial, para vencer las deficiencias que hoy se advierten. No precisa crear nuevos Tribunales cuyo montaje implicaría un gasto excesivo; basta perfeccionar los existentes, asignando una remuneración o premio especial para los funcionarios 
que actúan en los Tribunales provinciales, con el obligado refuerzo de personal auxiliar y disponibilidades de material, que hoy son verdaderamente irrisorias y que acusan una falta de preocupación e interés por este servicio verdacleramente trascendental.

Está bien la gratuidad del procedimiento como estímulo poderoso para que el ciudadano se defienda, pero no pueden olvidarse el mayor eșfuerzo que se le exige a unos funcionarios, simultaneando esta tarea con otra principal, y por ello sería obligado una remuneración especial y un complemento, tanto en la plantilla de auxiliares como los medios materiales para la realización de este cometido tan importante. Es curioso apreciar cómo en los tiempos modernos se conceden dietas para menesteres o actuaciones de menos trascendencia social y jurídica, así como el Consejo provincial del Instituto Nacional de Previsión por cada sesión mensual asigna 100 pesetas en dietas para los Consejeros que asisten a la sesión, en las que normalmente se resuelven asuntos de trámite, y en el Jurado provincial de estimación de la nueva Ley de Expropiación forzosa se establece también sistema de retribución y así en otros servicios de menos trascendencia, de muchas menores dificultades e inferior rango social que los Tribunales provinciales.

Deben, por tanto, subsistir los Tribunales provinciales, reorganizados convenientemente, y con una dotación económica que estimule su asidua actuación. En otra ocasión expusimos cuán innecesaric es hoy la presencia de los llamados "Vocales Administrativos» (2), reminiscencia de épocas pasadas, en que la doctrina de la división de los poderes del Estado arbitró esta fórmula, compensadora o neutralizadora, más exactamente, del llamado Poder judicial, incorporando a estos Tribunales dos miembros enraizados en el llamado Poder ejecutivo; y como es sabido, fueron dos Diputados provinciales hasta que fueron sustituídos por los llamados Vocales seleccionados de los distintos cuerpos de la Administración que la Ley marcaba. Hoy está superada la doctrina de la división de poderes y la función judicial se realiza por los Jueces y Magistrados con plena capacidad y un sentido jurídico admirable, sin que

(2) Vid. Nuevas notas sobre lo contencioso-administrativo. 


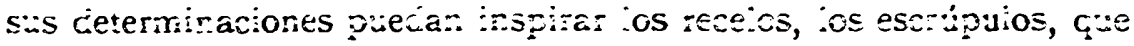
:uvieron en cuenta :os legis!aciores ciel sig.o pasado, $y$, por elio, er:tenciemos cue deje quedar integrado el Tribura: con funcionarios judiciaies, ya que su elevacio espíritu de justicia, su gran capacidać, sen garantías suficientes para una actuación acertada, sịn necesitacontrol de tipo administrativo que, como varias veces expusimos, constituye una rémora y una dificultad para la actuación de los mismos, ya que incluso aun en las ciudades en las que hay Un:versidad, la posibilidad de incorporar dos vocales de la mayor solvencia y garantía científica, mediante la incorporación de dos Catedráticos de la Facultad de Derecho, no siempre se logra, pues sea por falta de vocación para la función judicial, o sea por no querer limitarse sus actividades como Abogados libres, con frecuencia se excusan, alegando causas fundadas para ser relevados de dicha función.

Búsquense èstímulos para que los dignos Magistrados consagrados a la tarea de hacer justicia, se sientan atraídos por lo contencioso-administrativo, y simplifíquese el procedimiento ahorrando trámites, muchos de ellos totalmente innecesarios y dése cumplimiento a la Ley, a esa Ley de 1894, que tan admirable encauzamiento dió a esta jurisdicción, no obstante las corruptelas de la política pasada, cuyos preceptos han sido refundidos por el Decreto de 8 de febrero de 1952, con los particulares que regulaban lo contencioso-administrativo municipal, incorporando al mismo interesantes creaciones de la doctrina científica moderna que deben ser tenidos en cuenta para su perfeccionamiento en las futuras ordenaciones. que de lo contencioso-administrativo se haga.

Da pena ver cómo en la práctica lo contencioso-administrativo apenas merece atención, contrastando con el cuidado puritanismo de orden procesal, que se advierte, por ejemplo, en las actuaciones de la jurisdicción ordinaria, tanto en lo civil como en lo criminal. Es cierto que hay ese desvío, pero esto puede corregirse con estímulos de orden económico y de orden funcional si la jerarquía de los servicios de justicia se deciden a ello, dando continuidad a la actuación de estos Tribunales que no deben sufrir la rotación anual, en cuanto a su integración, como acontece en las Audiencias territo- 
riales, por lo que se rompe la uniformidad de criterio, la unidiad de juicio que tan interesante es mantener.

Gran parte de los males que hemos señalado a la actuación de lo contencioso-administrativo y que ilustres tratadistas han criticado acerbamente, tienen una causa única, sencillamente, que no se cumple la Ley. En el año 1933 (3) decíamos : "Son muchos los obstáculos que se oponen a la mayor eficacia de esta jurisdicción; la mayoría de ellos nacidos de una práctica viciosa que ha desfigurado ciertos preceptos legales, consignados para casos y situaciones especiales, generalizando su aplicación de forma que cualquier litigante temerario se acoja a tales preceptos, alargando a su capricho la resolución de estos litigios, ya que el impulso procesal se confía en nuestro derecho a las partes, olvidando o postergando el interés público latente en toda contienda con la Administración públican. Desde entonces ha sido muy poco lo que se ha adelantado y con frecuencia surgen aumentados los "obstáculos procesales" que entonces señalábamos, el retraso en el envío del expediente gubernativo, la ampliación del mismo, el recibimiento a prueba tardío e innecesario. Por otra parte, el sistema mantenido en el orden procesal concebido a fines del siglo xIx, no es el adecuado para el momento presente, y urge realmente poner remedio a esas deficiencias que no les son imputables a los Tribunales provinciales, sino que derivan de la imperfección del sistema procesal mantenido, imperfecciones que deben ser corregidas si hemos de lograr dar efectividad a los pronunciamientos de los Tribunales contencioso-administrativos. En efecto, una de las mayores lagunas de nuestro sistema se refiere a la ejecución de las sentencias. Es antijurídico que los fallos de los Tribunales de lo contencioso no se ejecuten, y que ello sea precisamente por determinación del propio organismo administrativo.

Resulta paradójico que cuando una Corporación municipal dicta un acuerdo, que es sometido a recurso contencioso-administrativo, si el Tribunal lo confirma, sea la propia Corporación la que

(3) Notas sobre lo contencioso-administrativo. Prólogo de D. Diego María Crehuet. 
luego no lo ejecute; ocurre esto con frecuencia, cuando a lo largo del proceso ha habido cambio en los elementos que integran el Consejo, no sienten la unidad de la Corporación y sí la demolición acordada, o si la declaración de ruina del edificio afecta a un amigo, se demora escandalosamente la ejecución de la sentencia, creando así una situación de rebeldía y desacato, situaciones que deben evitarse mediante una intervención asidua y eficiente del Fiscal de la Jurisdicción, porque de nada valdrá que se dicten sentencias muy perfectas, si no se llevan a efecto sus pronunciamientos.

Para la realización y ejecución de las sentencias de lo contencioso-administrativo, estimamos también que ofrece ventaja el Tribunal provincial sobre el Tribunal regional, y bastará con ello que en cada uno de los Tribunales se vigile "las ejecuciones", para lograr de esta forma que se lleven a cumplidos efectos las sentencias, así como también la eliminación de los obstáculos de tipo procesal que hemos enunciado y que, como decimos, han sido fustigados por nuestros ilustres administrativistas, y cuya condenación culminó en el célebre discurso del que fué Presidente insigne del Tribunal Supremo, el señor Ciudad Aurioles.

Cirilo Martin-Retortillo

A bogado del Estado 